\title{
Nationwide Outcome of Gastrectomy with En-Bloc Partial Pancreatectomy for Gastric Cancer
}

\author{
L. R. van der Werf ${ }^{1}$ (D) W. J. Eshuis ${ }^{2} \cdot$ W. A. Draaisma ${ }^{3} \cdot$ B. van Etten ${ }^{4} \cdot$ S. S. Gisbertz ${ }^{2}$ E. van der Harst ${ }^{5}$ - M. S. L. Liem ${ }^{6}$.

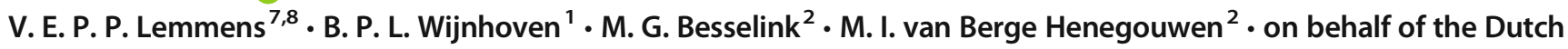 \\ Upper Gastrointestinal Cancer Audit (DUCA) group.
}

Received: 6 November 2018 / Accepted: 22 January 2019 / Published online: 28 February 2019

(C) 2019 The Author(s)

\begin{abstract}
Background Radical gastrectomy is the cornerstone of the treatment of gastric cancer. For tumors invading the pancreas, en-bloc partial pancreatectomy may be needed for a radical resection. The aim of this study was to evaluate the outcome of gastrectomies with partial pancreatectomy for gastric cancer.

Methods Patients who underwent gastrectomy with or without partial pancreatectomy for gastric or gastro-oesophageal junction cancer between 2011 and 2015 were selected from the Dutch Upper GI Cancer Audit (DUCA). Outcomes were resection margin (pR0) and Clavien-Dindo grade $\geq$ III postoperative complications and survival. The association between partial pancreatectomy and postoperative complications was analyzed with multivariable logistic regression. Overall survival of patients with partial pancreatectomy was estimated using the Kaplan-Meier method.

Results Of 1966 patients that underwent gastrectomy, 55 patients $(2.8 \%)$ underwent en-bloc partial pancreatectomy. A pR0 resection was achieved in 45 of 55 patients ( $82 \%$ versus $85 \%$ in the group without additional resection, $P=0.82$ ). Clavien-Dindo grade $\geq$ III complications occurred in 21 of 55 patients ( $38 \%$ versus $17 \%, P<0.001)$. Median overall survival [95\% confidence interval] was 15 [6.8-23.2] months. For patients with and without perioperative systemic therapy, median survival was 20 [12.327.7] and 10 [5.7-14.3] months, and for patients with pR0 and pR1 resection, it was 20 [11.8-28.3] and 5 [2.4-7.6] months, respectively.

Conclusions Gastrectomy with partial pancreatectomy is not only associated with a pR0 resection rate of $82 \%$ but also with increased postoperative morbidity. It should only be performed if a pR0 resection is feasible.
\end{abstract}

M. G. Besselink and M. I. van Berge Henegouwen contributed equally to this work.

Electronic supplementary material The online version of this article (https://doi.org/10.1007/s11605-019-04133-z) contains supplementary material, which is available to authorized users.

L. R. van der Werf

1 Department of Surgery, Erasmus University Medical Center, Rotterdam, the Netherlands

2 Department of Surgery, Cancer Center Amsterdam, Amsterdam University Medical Centre, University of Amsterdam, Amsterdam, the Netherlands

3 Department of Surgery, Meander Medical Centre, Amersfoort, the Netherlands
4 Department of Surgery, University Medical Centre Groningen, Groningen, the Netherlands

5 Department of Surgery, Maasstad Hospital, Rotterdam, the Netherlands

6 Department of Surgery, Medisch Spectrum Twente, Enschede, the Netherlands

7 Department of Pubic Health, Erasmus University Medical Centre, Rotterdam, the Netherlands

8 Department of Research, Comprehensive Cancer Organisation the Netherlands, Utrecht, the Netherlands 
Keywords Partial pancreatectomy $\cdot$ Gastric cancer $\cdot$ Gastrectomy $\cdot \mathrm{R} 0$ resection $\cdot$ Multiviceral resection

\section{Introduction}

The mainstay of curative treatment in gastric cancer is surgery. For patients with resectable gastric cancer of stage II or higher, neoadjuvant or adjuvant chemotherapy is recommended. ${ }^{1} \mathrm{~A}$ radical resection with tumor-negative resection margins ( $\mathrm{pR} 0$ resection) is the most powerful predictor of survival. ${ }^{2,3}$

In patients with advanced gastric cancer, en-bloc partial pancreatectomy may be needed to obtain a pR0 resection. However, the benefits of en-bloc partial pancreatectomy should be critically evaluated given the potential for increased morbidity. Routine splenectomy in patients who underwent a D2 gastrectomy did not lead to increased survival. ${ }^{4-6}$ In the past, a gastrectomy with pancreatosplenectomy was regarded as the standard of care for gastric cancer because it was believed that this would increase lymph node yield and thereby improve oncological outcomes. Since two large trials demonstrated that a D2 lymphadenectomy with pancreatosplenectomy increases postoperative morbidity and mortality without any additional beneficial effects on survival, ${ }^{7-9}$ current guidelines recommend a D2 resection without pancreatosplenectomy. ${ }^{1}$ Nowadays, an en-bloc partial pancreatectomy is only indicated for tumors that invade the pancreas. ${ }^{1}$

The aim of this study was to evaluate patient characteristics and outcomes of en-bloc partial pancreatectomies in patients undergoing gastrectomy for gastric cancer in the Netherlands between 2011 and 2015.

\section{Methods}

\section{Study Population}

For this study, the database of the Dutch Upper Gastrointestinal Cancer Audit (DUCA) was used. Participation in this national audit registry is mandatory for all Dutch hospitals that perform oncological upper gastrointestinal surgery. All patients with gastric or oesophageal cancer who are scheduled to undergo resection are included. ${ }^{10}$ In this audit, patient, disease, and treatment characteristics are prospectively collected. Outcomes are registered until 30 days postoperatively or during hospitalization. The completeness of cases registered in the DUCA approached $100 \%$ of patients registered in $2013 .^{10}$

Patients who underwent gastrectomy between 2011 and 2015 were selected from the DUCA (Fig. 1). Patients with missing 30-day mortality status $(n=27)$, date of birth $(n=$ $3)$, or type of procedure $(n=4)$ were excluded. When a partial pancreatectomy was registered as an additional surgical procedure, details of patient, treatment, and (long-term) outcome characteristics were provided by participating centers. Patients in whom the partial pancreatectomy was erroneously registered were excluded. For the comparison of patients with and without partial pancreatectomy, patients with other additional resections than pancreatectomy (e.g., splenectomy) were excluded. A separate analysis was executed to compare the occurrence of complications, in patients with partial pancreatectomy compared to patients with other additional (nonpancreas) resections. Another subgroup analysis was executed for patients with a pT4 tumor, the occurrence of complications in patients with partial pancreatectomy was compared to the occurrence of complications in patients without a partial pancreatectomy.

\section{Outcomes}

The prevalence of partial pancreatectomy for gastric cancer was analyzed for all individual hospitals. Characteristics and short-term outcomes of patients with a partial pancreatectomy were evaluated and compared with patients with no additional resection. Also, short-term outcomes were described for both groups: duration of hospital stay, intensive care unit (ICU) stay, resection margins (tumor negative: $\mathrm{pR} 0$, microscopically positive: $\mathrm{pR} 1$, macroscopically positive: $\mathrm{pR} 2$ ), postoperative complications, postoperative Clavien-Dindo grade $\geq$ III complications (defined as a complication in combination with a reintervention, readmission to the intensive care unit/medium care unit or death), and 30-day/in-hospital mortality.

Disease-free and overall survival for patients with partial pancreatectomy were evaluated. The following subgroups within the partial pancreatectomy group were compared: $\mathrm{pR} 0$ versus $\mathrm{pR} 1$ resections and perioperative systemic therapy versus no perioperative systemic therapy.

\section{Statistical Analysis}

Characteristics and short-term outcomes of patients who underwent gastrectomy with and without partial pancreatectomy were compared using Mann-Whitney $U$ test and chisquare test, when appropriate. The association between partial pancreatectomy and complications was tested with univariable and multivariable logistic regression analysis. In the multivariable analysis, clinically relevant variables were added to the model, as well as the variables that were associated with complications ( $P$ value $<0.10$ in univariable analyses). The association was tested for sex, age, Charlson comorbidity score, ${ }^{11}$ American Society of Anaestesiologists (ASA) score, tumor location, cT category, and $\mathrm{cN}$ category. Overall 


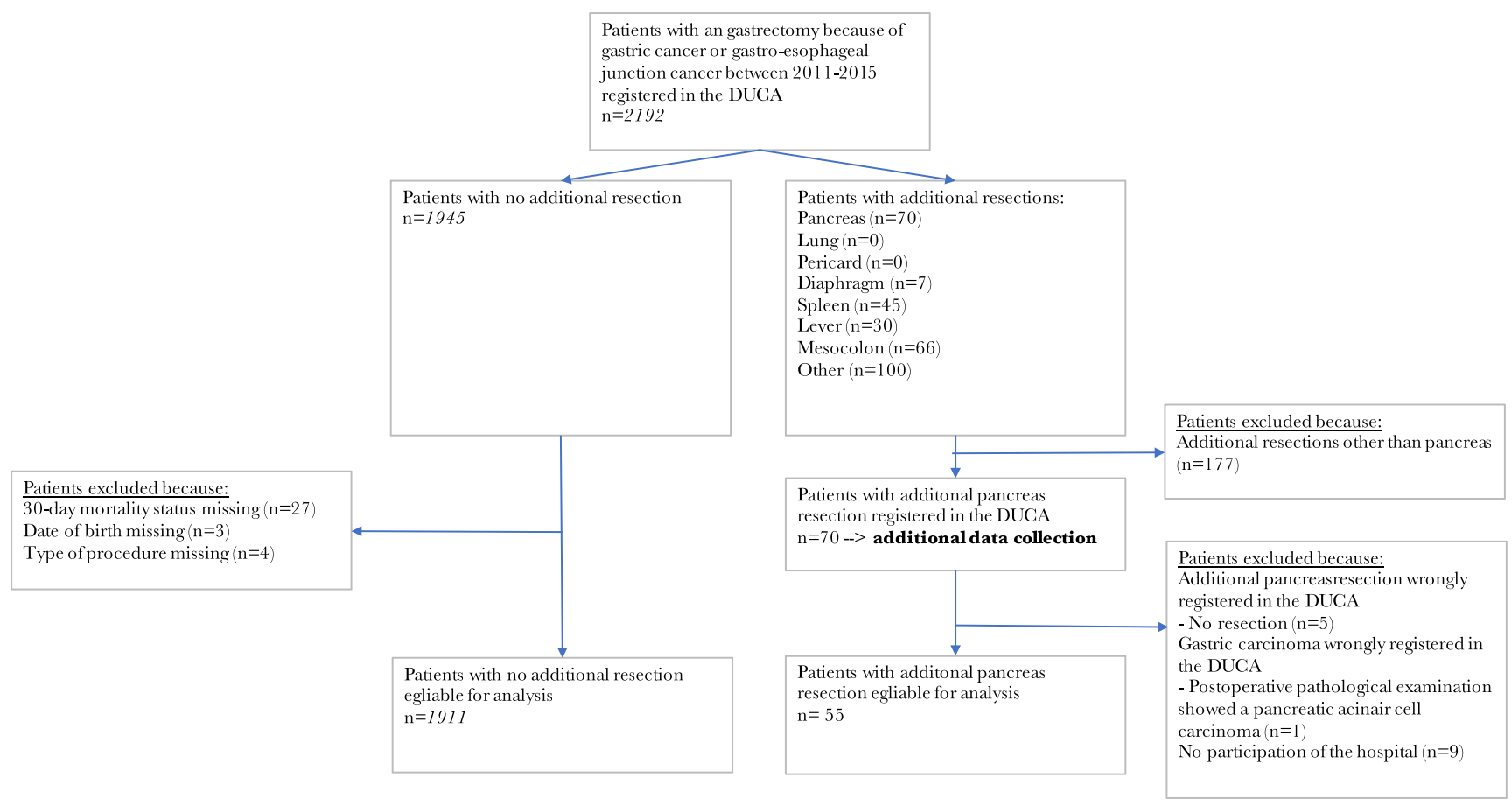

Fig. 1 Patients who underwent gastrectomy between 2011 and 2015

survival was estimated using the Kaplan-Meier method, and subgroups were compared with log-rank analysis. All analyses were performed using SPSS $®$ version 24 (IBM, Armonk, NY, USA).

\section{Results}

\section{Patients}

Between 2011 and 2015, 2192 patients who underwent a gastrectomy for gastric cancer were registered in the DUCA database. Additional resections were performed in 177 of 2192 patients $(8.1 \%)$. An additional partial pancreatectomy was performed in 70 of 2192 patients (3.2\%) (Fig. 1). The percentage gastrectomies with additional partial pancreatectomy varied between 0 and $10 \%$ for the individual hospitals.

Some 55 of 70 patients who underwent additional partial pancreatectomy were included in the analysis because all data could be retrieved from the patient charts. After exclusion of patients with incomplete data, 1911 patients without additional resections served as the control group.

Patient demographics are shown in Table 1 . In 12 of 55 patients who underwent a partial pancreatectomy, the tumor was staged preoperatively as cT4. In all 55 patients a preoperative CT scan was performed. In 15/55 (27\%) patients, preoperative EUS was performed.

In the additional pancreatectomy group, total gastrectomy was performed in 31 patients (56\%), and 34 patients received perioperative systemic therapy (62\%) (Table 2). Additional resections of adjacent organs/structures were performed in 31 of 55 patients, including the spleen $(n=25)$, mesocolon $(n=7)$, liver $(n=4)$, diaphragm $(n=1)$, and other $(n=10)$. Five of 27 patients with a distal pancreatectomy did not undergo a splenectomy. The remaining patients who underwent a splenectomy, $n=3$, underwent a wedge resection/pancreatic head resection. Upon pathological examination, 34 (62\%) tumors were staged as pT4 (Table 2).

\section{Operations}

Nine of 55 patients (16\%) underwent pancreatoduodenectomy, $27(49 \%)$ distal pancreatectomy, and $19(35 \%)$ a wedge resection (Table 3$)$. In the vast majority $(n=52)$, the indication for partial pancreatectomy was direct tumor ingrowth into the pancreas. Some 30 of 55 resections were performed by a surgeon with experience in pancreatic surgery. In $6(11 \%)$ procedures, the surgical team was changed for the pancreatectomy.

A pR0 resection was achieved in 45 of 55 patients undergoing gastrectomy with partial pancreatectomy (82\%) (Table 4). This was not statistically significant different from the patients who underwent a gastrectomy without additional resection (1617 of $1911,85 \%, P=0.82)$.

\section{Complications}

In the partial pancreatectomy group, there were relatively more patients with postoperative complications, $n=33(60 \%)$ versus 
Table 1 Patient and disease characteristics of patients undergoing gastrectomy with no additional resection and with additional partial pancreatectomy

\begin{tabular}{|c|c|c|c|c|c|}
\hline & \multicolumn{2}{|c|}{ Gastrectomy alone } & \multicolumn{2}{|c|}{ Gastrectomy plus partial pancreatectomy } & \multirow[t]{3}{*}{$P$ value } \\
\hline & \multicolumn{2}{|c|}{$n=1911(97 \%)$} & \multicolumn{2}{|c|}{$n=55(2.8 \%)$} & \\
\hline & $n$ & $\%$ & $n$ & $\%$ & \\
\hline Gender & & & & & 0.53 \\
\hline Male & 1207 & $63 \%$ & 37 & $67 \%$ & \\
\hline Female & 704 & $37 \%$ & 18 & $33 \%$ & \\
\hline Age (in years, median, IQR) & 70 & [62-77] & 66 & {$[57-73]$} & \\
\hline Age (in groups) & & & & & 0.04 \\
\hline$<65$ years & 605 & $32 \%$ & 22 & $40 \%$ & \\
\hline 65-74 years & 645 & $34 \%$ & 23 & $42 \%$ & \\
\hline$>75$ years & 661 & $35 \%$ & 10 & $18 \%$ & \\
\hline Charlson score & & & & & $<0.001$ \\
\hline 0 & 835 & $44 \%$ & 39 & $71 \%$ & \\
\hline 1 & 458 & $24 \%$ & 7 & $13 \%$ & \\
\hline $2+$ & 618 & $32 \%$ & 9 & $16 \%$ & \\
\hline ASA score & & & & & 0.71 \\
\hline I-II & 1293 & $68 \%$ & 39 & $71 \%$ & \\
\hline III+ & 600 & $31 \%$ & 16 & $29 \%$ & \\
\hline Unknown & 18 & $0.9 \%$ & 0 & $0.0 \%$ & \\
\hline Location of tumor & & & & & 0.05 \\
\hline Esophageal-gastric junction & 69 & $3.6 \%$ & 1 & $1.8 \%$ & \\
\hline Fundus & 134 & $7.0 \%$ & 8 & $15 \%$ & \\
\hline Corpus & 556 & $29 \%$ & 16 & $29 \%$ & \\
\hline Antrum & 771 & $40 \%$ & 13 & $24 \%$ & \\
\hline Pylorus & 153 & $8.0 \%$ & 9 & $16 \%$ & \\
\hline Entire stomach & 95 & $5.0 \%$ & 3 & $5.5 \%$ & \\
\hline Pouch & 59 & $3.1 \%$ & 3 & $5.5 \%$ & \\
\hline Unknown & 74 & $3.9 \%$ & 2 & $3.6 \%$ & \\
\hline cT category & & & & & $<0.001$ \\
\hline cT0-2 & 571 & $30 \%$ & 2 & $3.6 \%$ & \\
\hline cT3 & 763 & $40 \%$ & 27 & $49 \%$ & \\
\hline cT4 & 78 & $4.1 \%$ & 12 & $22 \%$ & \\
\hline $\mathrm{cTx}$ & 457 & $24 \%$ & 14 & $26 \%$ & \\
\hline Missing & 42 & $2.2 \%$ & 0 & $0.0 \%$ & \\
\hline $\mathrm{cN}$ category & & & & & 0.002 \\
\hline $\mathrm{cN}-0$ & 976 & $51 \%$ & 15 & $27 \%$ & \\
\hline $\mathrm{cN}+$ & 661 & $35 \%$ & 28 & $51 \%$ & \\
\hline $\mathrm{cNx}$ & 231 & $12 \%$ & 12 & $22 \%$ & \\
\hline Missing & 43 & $2.3 \%$ & 0 & $0.0 \%$ & \\
\hline cM category & & & & & 0.001 \\
\hline $\mathrm{cM}-0$ & 1774 & $93 \%$ & 49 & $89 \%$ & \\
\hline $\mathrm{cM}+$ & 24 & $1.3 \%$ & 4 & $7.3 \%$ & \\
\hline $\mathrm{cMx}$ & 113 & $5.9 \%$ & 2 & $3.6 \%$ & \\
\hline TNM stage & & & & & n.a. \\
\hline Stage 0 & 33 & $1.8 \%$ & 0 & $0.0 \%$ & \\
\hline Stage I & 392 & $21 \%$ & 1 & $1.8 \%$ & \\
\hline Stage II & 637 & $35 \%$ & 17 & $31 \%$ & \\
\hline Stage III & 138 & $8 \%$ & 8 & $15 \%$ & \\
\hline Stage IV & 24 & $1.3 \%$ & 3 & $5.5 \%$ & \\
\hline Stage unknown & 687 & $36 \%$ & 26 & $47 \%$ & \\
\hline
\end{tabular}

IQR interquartile range, ASA American Society Anaesthesiologists, n.a. not available

$n=703(37 \%, P \leq 0.001)$ (Table 4). Also, Clavien-Dindo grade III and higher complications occurred more frequently in the partial pancreatectomy group: in 21 (38\%) patients versus 332 $(17 \%)$ patients $(<0.001)$. An additional partial pancreatectomy was independently associated with a complication with ClavienDindo grade III or higher (OR [95\% confidence interval (CI)] 3.28 [1.85-5.82] (Table 4). Postoperative pancreatic fistulas grade $\mathrm{B}$ and $\mathrm{C}$ according to the International Study Group on
Pancreatic Surgery definition were observed in 9 (16\%) and 2 $(3.6 \%)$ patients, respectively (Table 5). ${ }^{12}$ Clavien-Dindo grade III or higher occurred in 42/172 $(24 \%)$ patients with other additional (non-pancreas) resections; this was not significantly different from the partial pancreatectomy group (38\%). For the subgroup of patients with a pT4 tumor, 332/1911 (17\%) patients in the gastrectomy only group had a Clavien-Dindo grade III or higher complication versus $4 / 24(17 \%)$ of patients in the partial 
Table 2 Treatment characteristics of patients undergoing gastrectomy with no additional resection and with additional partial pancreatectomy

\begin{tabular}{|c|c|c|c|c|c|}
\hline \multirow{3}{*}{ Treatment } & \multicolumn{2}{|c|}{ Gastrectomy alone } & \multicolumn{2}{|c|}{ Gastrectomy plus partial pancreatectomy } & \multirow[t]{3}{*}{$P$ value } \\
\hline & \multicolumn{2}{|c|}{$n=1911(97 \%)$} & \multicolumn{2}{|c|}{$n=55(2.8 \%)$} & \\
\hline & $n$ & $\%$ & $n$ & $\%$ & \\
\hline (Neo)adjuvant therapy & & & & & 0.28 \\
\hline None & 779 & $42 \%$ & 21 & $38 \%$ & \\
\hline Neoadjuvant and adjuvant & 688 & $37 \%$ & 17 & $31 \%$ & \\
\hline Adjuvant & 44 & $2 \%$ & 3 & $6 \%$ & \\
\hline Neoadjuvant & 358 & $19 \%$ & 14 & $26 \%$ & \\
\hline Urgency of surgery & & & & & 0.01 \\
\hline Elective & 1833 & $96 \%$ & 49 & $89 \%$ & \\
\hline Urgent/emergency & 75 & $4 \%$ & 6 & $11 \%$ & \\
\hline Unknown & 3 & $0 \%$ & 0 & $0 \%$ & \\
\hline Curative/palliative & & & & & n.a. \\
\hline Palliative & 52 & $3 \%$ & 3 & $6 \%$ & \\
\hline Curative & 1835 & $96 \%$ & 51 & $93 \%$ & \\
\hline Prophylactic resection & 13 & $1 \%$ & 0 & $0 \%$ & \\
\hline Unknown & 11 & $1 \%$ & 1 & $2 \%$ & \\
\hline Type of resection & & & & & 0.03 \\
\hline Total gastrectomy & 803 & $42 \%$ & 31 & $56 \%$ & \\
\hline Partial gastrectomy & 1108 & $58 \%$ & 24 & $44 \%$ & \\
\hline Procedure & & & & & n.a. \\
\hline Open & 1331 & $70 \%$ & 44 & $80 \%$ & \\
\hline MI abdomen & 489 & $26 \%$ & 5 & $9 \%$ & \\
\hline MI abdomen converted & 56 & $2.9 \%$ & 6 & $11 \%$ & \\
\hline MI thorax & 1 & $0.1 \%$ & 0 & $0.0 \%$ & \\
\hline MI thorax and abdomen & 14 & $0.7 \%$ & 0 & $0.0 \%$ & \\
\hline MI thorax and abdomen converted & 3 & $0.2 \%$ & 0 & $0.0 \%$ & \\
\hline Unknown & 17 & $1 \%$ & 0 & $0 \%$ & \\
\hline Reconstruction & & & & & n.a. \\
\hline No reconstruction & 36 & $2 \%$ & 1 & $2 \%$ & \\
\hline Gastric tube & 17 & $1 \%$ & 1 & $2 \%$ & \\
\hline Coloninterponate & 2 & $0 \%$ & 0 & $0 \%$ & \\
\hline Jejunuminterponate & 39 & $2.0 \%$ & 0 & $0.0 \%$ & \\
\hline Esophagojejunostomy & 776 & $41 \%$ & 30 & $55 \%$ & \\
\hline Gastro-enterostomy & 1007 & $53 \%$ & 22 & $40 \%$ & \\
\hline Other & 9 & $1 \%$ & 1 & $2 \%$ & \\
\hline Unknown & 25 & $1 \%$ & 0 & $0 \%$ & \\
\hline Additional resections other than pancreatic & & & 31 & $56 \%$ & \\
\hline Spleen (intentional) & & & 25 & $45 \%$ & \\
\hline Diaphragm & & & 1 & $1.8 \%$ & \\
\hline Liver & & & 4 & $7.2 \%$ & \\
\hline Mesocolon & & & 7 & $13 \%$ & \\
\hline Other & & & 10 & $19 \%$ & \\
\hline Pathological T-stage & & & & & $<0.001$ \\
\hline pT0-2 & 728 & $38 \%$ & 3 & $6 \%$ & \\
\hline pT3 & 753 & $39 \%$ & 17 & $31 \%$ & \\
\hline pT4 & 371 & $19 \%$ & 34 & $62 \%$ & \\
\hline $\mathrm{pTx}$ & 29 & $2 \%$ & 1 & $2 \%$ & \\
\hline Unknown & 30 & $2 \%$ & 0 & $0 \%$ & \\
\hline Annual volume in the hospital or resection & & & & & 0.20 \\
\hline $0-19$ resections & 1217 & $64 \%$ & 37 & $67 \%$ & \\
\hline 20-39 resections & 481 & $25 \%$ & 16 & $29 \%$ & \\
\hline 40 or more resections & 213 & $11 \%$ & 2 & $4 \%$ & \\
\hline
\end{tabular}

MI minimally invasive, n.a. not available

pancreatectomy group $(P=0.93)$. Combined in-hospital and 30day mortality was $7.3 \%$ (4 of 53) in patients with partial pancreatectomy versus $5.3 \%$ in patients without additional resections (101 of 1911, $P=0.52$ ) (Table 4).

\section{Survival}

Median follow-up of the patients with partial pancreatectomy was 42 [95\% CI 36.1-47.9] months. Median overall survival was 15 [6.8-23.2] months (Fig. 2a), and median disease-free 
Table 3 Details of the partial pancreatectomies: treatment characteristics

Partial pancreatectomies

\begin{tabular}{|c|c|c|c|c|c|c|c|c|}
\hline & \multicolumn{2}{|c|}{ Total } & \multicolumn{2}{|c|}{ Pancreatoduodenectomy } & \multicolumn{2}{|c|}{$\begin{array}{l}\text { Distal } \\
\text { pancreatectomy }\end{array}$} & \multicolumn{2}{|c|}{$\begin{array}{l}\text { Minimal/ } \\
\text { wedge } \\
\text { resection }\end{array}$} \\
\hline & 55 & & $\begin{array}{l}n \\
9\end{array}$ & $\begin{array}{l}\% \\
16 \%\end{array}$ & $\begin{array}{l}n \\
27\end{array}$ & $\begin{array}{l}\% \\
49 \%\end{array}$ & $\begin{array}{l}n \\
19\end{array}$ & $\begin{array}{l}\% \\
35 \%\end{array}$ \\
\hline \multicolumn{9}{|l|}{ Indication pancreas resection } \\
\hline Tumor growth in pancreas & 52 & $95 \%$ & 9 & $100 \%$ & 25 & $93 \%$ & 18 & $95 \%$ \\
\hline Intraoperative injury pancreas & 0 & $0.0 \%$ & 0 & $0.0 \%$ & 0 & $0.0 \%$ & 0 & $0.0 \%$ \\
\hline Lymph node dissection & 3 & $5.5 \%$ & 0 & $0.0 \%$ & 2 & $7.4 \%$ & 1 & $5.3 \%$ \\
\hline Other & 0 & $0.0 \%$ & 0 & $0.0 \%$ & 0 & $0.0 \%$ & 0 & $0.0 \%$ \\
\hline \multicolumn{9}{|l|}{ Type of surgeon } \\
\hline Surgeon with expertise in pancreassurgery ${ }^{a}$ & 30 & $55 \%$ & 7 & $78 \%$ & 14 & $52 \%$ & 9 & $47 \%$ \\
\hline Surgeon with expertise in upper GI surgery & 25 & $46 \%$ & 2 & $22 \%$ & 13 & $48 \%$ & 10 & $53 \%$ \\
\hline \multicolumn{9}{|l|}{ Change in surgical team } \\
\hline No & 49 & $89 \%$ & 8 & $89 \%$ & 24 & $89 \%$ & 17 & $90 \%$ \\
\hline Yes, preoperative & 2 & $3.6 \%$ & 0 & $0.0 \%$ & 1 & $3.7 \%$ & 1 & $5.3 \%$ \\
\hline Yes, intraoperative & 4 & $7.3 \%$ & 1 & $11 \%$ & 2 & $7.4 \%$ & 1 & $5.3 \%$ \\
\hline \multicolumn{9}{|l|}{ Type of reconstruction } \\
\hline No & 45 & $82 \%$ & 3 & $33 \%$ & 24 & $89 \%$ & 18 & $95 \%$ \\
\hline $\begin{array}{l}\text { Pancreatico-jejunostomy, hepato-jejunostomy, } \\
\text { and gastro-jejunostomy }\end{array}$ & 8 & $15 \%$ & 6 & $67 \%$ & 2 & $7.4 \%$ & 0 & $0.0 \%$ \\
\hline Other & 2 & $3.6 \%$ & 0 & $0.0 \%$ & 1 & $3.7 \%$ & 1 & $5.3 \%$ \\
\hline \multicolumn{9}{|l|}{ Drain in pancreatic region (intraoperative) } \\
\hline Yes & 16 & $29 \%$ & 4 & $44 \%$ & 5 & $19 \%$ & 7 & $37 \%$ \\
\hline No & 39 & $71 \%$ & 5 & $56 \%$ & 22 & $82 \%$ & 12 & $63 \%$ \\
\hline \multicolumn{9}{|l|}{ Drain in pancreatic region (postoperative, percut.) } \\
\hline Yes & 45 & $83 \%$ & 7 & $78 \%$ & 23 & $85 \%$ & 15 & $83 \%$ \\
\hline No & 9 & $17 \%$ & 2 & $22 \%$ & 4 & $15 \%$ & 3 & $17 \%$ \\
\hline
\end{tabular}

${ }^{\mathrm{a}}$ In the last year

survival was 13 [7.6-18] months (Fig. 2b). One-, 2-, and 3year survival rates were $56 \%, 38 \%$, and $31 \%$, respectively. In patients in whom an pR0 resection was obtained, median overall survival was 20 [11.8-28.3] months and for patients with an pR1 resection, 5 [2.4-7.6] months (Fig. 2c). For patients treated with perioperative systemic therapy, median overall survival was 20 [12.3-27.7] months versus 10 [5.714.3] months for patients without perioperative systemic therapy (Supplementary Fig. 1).

\section{Discussion}

A gastrectomy with en-bloc partial pancreatectomy was rarely performed in the Netherlands between 2011 and 2015. The intraoperative indication for partial pancreatectomy for gastric cancer was usually direct tumor ingrowth in the pancreas. In these patients, additional partial pancreatectomy was associated with an R0 resection rate of $82 \%$ but an increased risk for complications.

This study gives a unique overview of the national outcome of patients with gastric cancer for whom an additional partial pancreatectomy was performed during gastrectomy. Most studies on additional resections evaluated different multivisceral resections as one group. ${ }^{4,13,14}$ The national audit database enabled the identification of patients who underwent an additional partial pancreatectomy during a gastrectomy. Because multiple centers participated, we could evaluate the outcomes of a reasonable large cohort of patients treated with gastrectomy with partial pancreatectomy in the Netherlands in the period 2011-2015.

One of the factors associated with improved survival was a radical (pR0) resection. Previous studies also showed a decreased survival in patients in whom an R0 resection could 
Table 4 Short-term outcomes of patients with no additional resections versus patients with additional partial pancreatectomies

\begin{tabular}{|c|c|c|c|c|c|}
\hline & \multicolumn{2}{|c|}{ Gastrectomy alone } & \multicolumn{2}{|c|}{$\begin{array}{l}\text { Gastrectomy plus partial } \\
\text { pancreatectomy }\end{array}$} & \multirow[t]{3}{*}{$P$ value } \\
\hline & \multicolumn{2}{|c|}{$n=1911(97 \%)$} & \multicolumn{2}{|c|}{$n=55(2.8 \%)$} & \\
\hline & Mean & Median [IQR] & Mean & Median [IQR] & \\
\hline Hospital stay (days) & 14 & $9[7-13]$ & 23 & $14[10-20]$ & $<0.001$ \\
\hline \multirow[t]{2}{*}{ IC stay (days) } & 1.8 & $0[0-1]$ & 1.8 & $1[0-2]$ & $>0.05$ \\
\hline & $n$ & $\%$ & $n$ & $\%$ & $P$ value \\
\hline Intraoperative complication & 73 & $3.8 \%$ & 1 & $1.8 \%$ & 0.44 \\
\hline Postoperative complication & 703 & $37 \%$ & 33 & $60 \%$ & $<0.001$ \\
\hline Reintervention & 279 & $15 \%$ & 20 & $36 \%$ & $<0.001$ \\
\hline Radiological & \multicolumn{2}{|l|}{83} & \multicolumn{2}{|l|}{11} & \\
\hline Endoscopic & \multicolumn{2}{|l|}{38} & \multicolumn{2}{|l|}{3} & \\
\hline Reoperation & \multicolumn{2}{|l|}{211} & \multicolumn{2}{|l|}{10} & \\
\hline In-hospital and 30-day mortality & 101 & $5.3 \%$ & 4 & $7.3 \%$ & 0.52 \\
\hline Clavien-Dindo grade $\geq$ III complication & 332 & $17 \%$ & 21 & $38 \%$ & $<0.001$ \\
\hline \multicolumn{5}{|l|}{ Resection margins } & \multirow[t]{6}{*}{0.82} \\
\hline R0 Microscopic radical & 1617 & $85 \%$ & 45 & $82 \%$ & \\
\hline R1 Microscopic irradical & 202 & $11 \%$ & 7 & $13 \%$ & \\
\hline R2 Loco regional residual tumor & 25 & $1.3 \%$ & 1 & $1.8 \%$ & \\
\hline Not applicable & 21 & $1.1 \%$ & 0 & $0.0 \%$ & \\
\hline Unknown & 46 & $2.4 \%$ & 2 & $3.6 \%$ & \\
\hline Multivariable analysis & \multicolumn{2}{|l|}{ OR } & \multicolumn{2}{|c|}{$95 \% \mathrm{CI}$} & $P$ value \\
\hline Association with Clavien-Dindo grade $\geq$ III complication ${ }^{\mathrm{a}}$ & & & & & $<0.001$ \\
\hline No additional resection & \multicolumn{2}{|l|}{1.00} & & \\
\hline Additional partial pancreatectomy & \multicolumn{2}{|l|}{3.13} & & $1.76-5.59$ & \\
\hline
\end{tabular}

${ }^{a}$ Adjusted for age, sex, Charlson comorbidity score, ${ }^{11}$ ASA score, location tumor, type of resection (partial/total gastrectomy)

$I C$ intensive care, $R 0$ tumor-negative resection margins, $R 1$ microscopically tumor-positive resection margins, $R 2$ macroscopically tumor-positive resection margins, $I Q R$ interquartile range, $C I$ confidence interval, ASA American Society Anaesthesiologists

not be achieved. ${ }^{13-16}$ In the present study, the percentage of $\mathrm{R} 0$ resections was comparable between the group of patients with partial pancreatectomy and without additional resections ( $82 \%$ versus $85 \%, P=0.82$ ). In the current literature, the percentages R0 resections after multivisceral resections range from 38 to $100 \% .{ }^{17}$ Tran et al. reported an R0 resection rate of $100 \%$ in 34 patients after additional partial pancreatectomy. ${ }^{18}$

In this study, only $22 \%$ of patients with an additional partial pancreatectomy had a cT4 tumor, and only $62 \%$ had a pT4 tumor at pathological examination. Ideally, a partial pancreatectomy should only be performed in actual T4 tumors. In other cohorts with multivisceral resections, low percentages of pT4 tumors have been reported as well (14-80\%). ${ }^{17}$ The low percentage of patients with a cT4 tumor shows that there is a discrepancy in the diagnostic assessment of tumor stage with the intraoperative assessment. In order to distinguish a cT3 tumor from a cT4 tumor in the preoperative phase, endoscopic ultrasound (EUS), multidetector row computed tomography (MDCT), and magnetic resonance imaging (MRI) are preferred imaging methods. ${ }^{19}$ Also, when it is not known whether there is ingrowth in the pancreas, it may be recommended to perform an EUS, MDCT, or MRI. The results of the DUCA showed that in only $27 \%$ of patients EUS is used for diagnostics. The use of MDCT and MRI were not registered in the DUCA.

The low percentage of patients with a pT4 tumor shows that there is a discrepancy in the intraoperative assessment of tumor stage with the actual tumor stage as seen in pathological examination. Intraoperative frozen section biopsy could be used to assess the resection margin and to decide whether an additonal pancreatectomy is needed. However, dissecting through the tumor plane violates the principle of surgical oncology, i.e., en-bloc resection.

In the present study, patients treated with perioperative systemic therapy had better survival. Selection bias might partly 
Table 5 Details of the partial pancreatectomies: treatment characteristics

Pancreatectomies

\begin{tabular}{|c|c|c|c|c|c|c|c|c|}
\hline & \multicolumn{2}{|c|}{ Total } & \multicolumn{2}{|c|}{ Pancreatoduodenectomy } & \multicolumn{2}{|c|}{ Distal pancreatectomy } & \multicolumn{2}{|c|}{ Minimal/wedge resection } \\
\hline & 55 & & $\begin{array}{l}n \\
9\end{array}$ & $\begin{array}{l}\% \\
16 \%\end{array}$ & $\begin{array}{l}n \\
27\end{array}$ & $\begin{array}{l}\% \\
49 \%\end{array}$ & $\begin{array}{l}n \\
19\end{array}$ & $\begin{array}{l}\% \\
35 \%\end{array}$ \\
\hline \multicolumn{9}{|l|}{ Postoperative complications } \\
\hline No & 22 & $40 \%$ & 2 & $22 \%$ & 10 & $37 \%$ & 10 & $53 \%$ \\
\hline Yes & 33 & $60 \%$ & 7 & $78 \%$ & 17 & $63 \%$ & 9 & $47 \%$ \\
\hline \multicolumn{9}{|l|}{ POFP $^{\mathrm{a}}$} \\
\hline No POPF, no biochemical leakage & 39 & $71 \%$ & 6 & $67 \%$ & 18 & $67 \%$ & 15 & $79 \%$ \\
\hline No POPF, but biochemical leakage & 5 & $9.1 \%$ & 1 & $11 \%$ & 4 & $15 \%$ & 0 & $0.0 \%$ \\
\hline Yes, grade B & 9 & $16 \%$ & 2 & $22 \%$ & 5 & $19 \%$ & 2 & $11 \%$ \\
\hline Yes, grade $\mathrm{C}$ & 2 & $3.6 \%$ & 0 & $0.0 \%$ & 0 & $0.0 \%$ & 2 & $11 \%$ \\
\hline \multicolumn{9}{|l|}{ Clavien-Dindo grade $\geq$ III complication } \\
\hline No & 34 & $62 \%$ & 3 & $33 \%$ & 19 & $70 \%$ & 12 & $63 \%$ \\
\hline Yes & 21 & $38 \%$ & 6 & $67 \%$ & 8 & $30 \%$ & 7 & $37 \%$ \\
\hline \multicolumn{9}{|l|}{ 30-day/in-hospital mortality } \\
\hline No & 51 & $93 \%$ & 8 & $89 \%$ & 26 & $96 \%$ & 17 & $90 \%$ \\
\hline Yes & 4 & $7.3 \%$ & 1 & $11 \%$ & 1 & $3.7 \%$ & 2 & $11 \%$ \\
\hline
\end{tabular}

${ }^{a}$ According to the definition of Bassi\&ISGPS, Surgery 2016

$P O P F$ postoperative pancreatic fistula

explain this difference. A recent study on the use of perioperative therapy in Dutch patients showed that older patients and patients with a higher ASA score had a lower probability for initiation of perioperative therapy. ${ }^{20}$ In the present cohort, the patients who were not treated with preoperative therapy might have been frail patients who were unfit for undergoing preoperative therapy. These patients are probably more likely to die which could have influenced the survival of this group. Furthermore, exclusion for resection of patients that are progressive during perioperative therapy could have occurred. These data are not available in our surgical database. However, based on our results, it may be wise to take the prognosis of patients without perioperative systemic therapy into account. Patients who are not eligible for perioperative systemic therapy may also not benefit from a partial pancreatectomy during gastrectomy.

Since the MAGIC trial, perioperative chemotherapy for gastric cancer gained importance. ${ }^{21}$ Since partial pancreatectomies are associated with high complication rates, it is possible that patients who undergo a partial pancreatectomy cannot be treated with adjuvant therapy. In the Dutch guideline, perioperative chemotherapy is recommended for patients with stage $>1$ gastric cancer and are fit enough to undergo chemotherapy. ${ }^{1}$ This study showed that $38 \%$ of patients in the pancreatectomy group were not treated with neoadjuvant therapy neither adjuvant therapy. A recent Dutch study showed that patients with postoperative complications had a threefold increased likelihood of not receiving adjuvant therapy. ${ }^{22}$ It might thus be prudent to focus on a more intense neoadjuvant systemic therapy to patients in whom a partial pancreatectomy is considered. In the future, the results of the CRITICS-II may help in choosing the best neoadjuvant therapy. The CRITICS-II trial aims to optimize preoperative treatment by comparing treatment regimens: (1) chemotherapy, (2) chemotherapy followed by chemoradiotherapy, and (3) chemoradiotherapy. $^{23}$

The performance of additional partial pancreatectomy and splenectomy in order to retrieve more lymph nodes abandoned in the past because of its high postoperative morbidity. 8,9

The current study showed high postoperative morbidity in gastrectomy patients with partial pancreatectomies. Complications occurred in $60 \%$ of patients, and ClavienDindo grade III and higher complications in $38 \%$ of patients. Tran et al. reported also a significantly higher percentage of Clavien-Dindo grade $\geq$ III complications for patients with gastric cancer undergoing a gastrectomy with partial pancreatectomy versus gastrectomy without multivisceral resection (33\% versus $17 \%){ }^{18,24}$ These results are comparable to pancreatic cancer patients: a recent study reported the postoperative outcomes of partial pancreatectomies for pancreatic cancer in the Netherlands; they showed that $30 \%$ of patients had a Clavien-Dindo grade III or higher complication. ${ }^{25}$

The survival rates in our study were comparable to those reported in a recent study by Mita et al. evaluating additional 
a
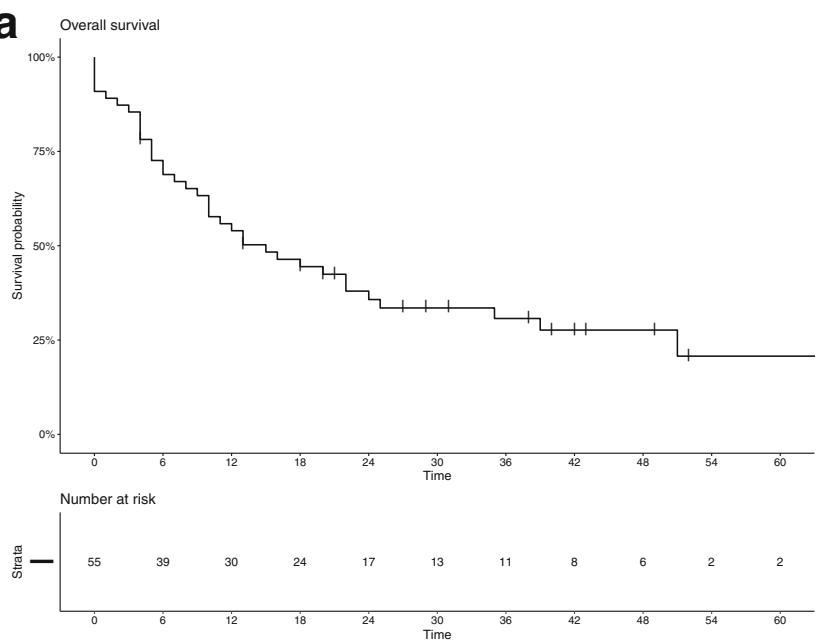

C

Overall survival
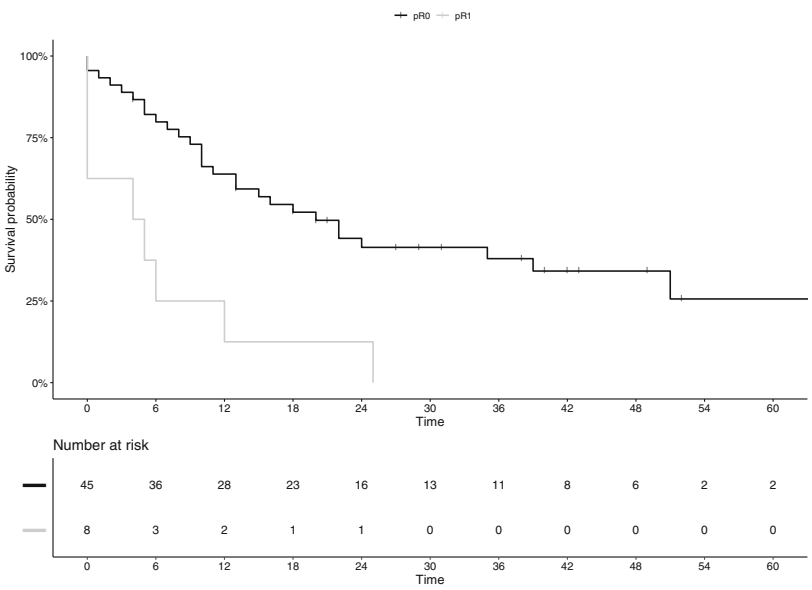

Fig. 2 Survival of patients with partial pancreatectomy

partial pancreatectomies for gastric cancer. They reported a 1year survival rate of $62 \%$ and a 3-year survival rate of $35 \%$ (versus respectively $56 \%$ and $31 \%$ in the present cohort). ${ }^{26}$ Likewise, the 3-year survival rates of patients with pT4 gastric cancer who underwent multivisceral resections are comparable with the outcomes in our cohort. ${ }^{27}$ Compared to the 2-year survival rate of all potentially curative gastric cancer patients in the Netherlands, the survival of this cohort is poor. ${ }^{28}$ Van Putten et al. reported national 2-year survival rates varying between 38 and 50\%, depending on the variation in surgical treatment probability between hospitals.

A limitation of this study was that a pancreatectomy for gastric cancer was not common and not all hospitals in the Netherlands participated in the data collection for patients with partial pancreatectomy. All hospitals have been contacted to participate. The hospitals that did not participate indicated that the reason was of a logistical nature (no time). A second limitation was that survival information was not available for the patients with gastrectomy only. b
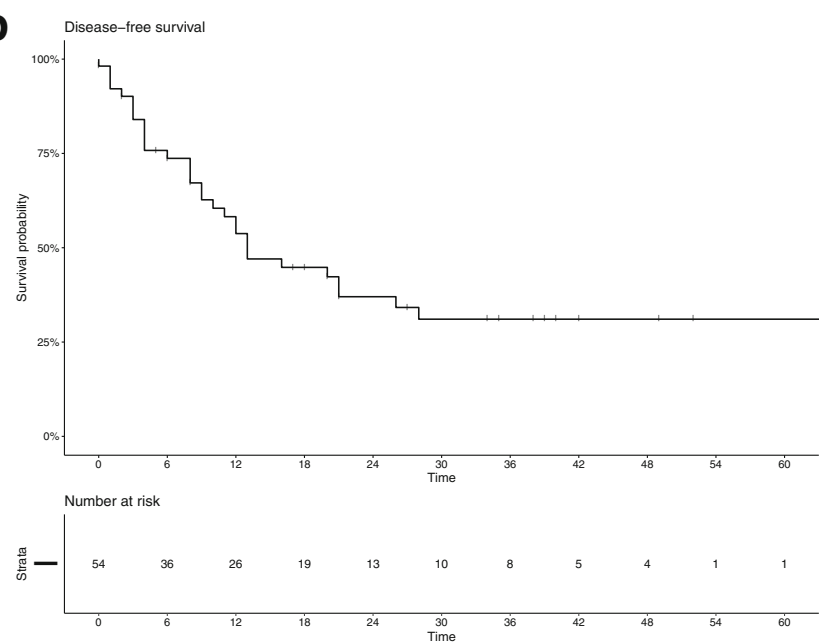

Another limitation was that it was not possible to determine the independent influence of individual parameters on survival because the number of patients undergoing partial pancreatectomy was relatively limited. Because of this limited number of patients, no conclusions could be drawn regarding the different types of pancreatectomies.

In conclusion, the present study showed that a gastrectomy in combination with a partial pancreatectomy might be considered as a valid curative treatment option for gastric cancer. The reported morbidity and mortality after partial pancreatectomy for gastric cancer are at least comparable to rates after partial pancreatectomy for pancreatic cancer. Therefore, despite the high morbidity, it may be worthwhile to perform a partial pancreatectomy in patients with gastric cancer when the tumor is directly invading into the pancreas. It should probably be reserved for patients with a T4 tumor in whom an R0 resection is feasible. Preoperative and intraoperative selection of patients for additional partial pancreatectomy might be the key to success. 
Acknowledgements The authors would like to thank all surgeons, registrars, physician assistants, and administrative nurses for data registration in the DUCA database, the Dutch Upper GI Cancer Audit group for scientific input, as well as the following persons who have contributed to this study:

R. van Hillegersberg, MD PhD, Department of Surgery, University Medical Centre Utrecht, Utrecht, the Netherlands

Y. van Eijden, Department of Surgery, Zuyderland Hospital, Heerlen, the Netherlands

S. van Esser, MD PhD, Department of Surgery, Reinier de Graaf Hospital, Delft, the Netherlands

H. H. Hartgrink, MD PhD, Department of Surgery, Leiden University Medical Centre, Leiden, the Netherlands

G. de Jong, MD PhD, Department of Surgery, Rijnstate Hospital, Arnhem, the Netherlands

T. M. Karsten, MD PhD, Department of Surgery, Onze Lieve Vrouwe Hospital, Amsterdam, the Netherlands

E. A. Kouwenhoven, MD PhD, Department of Surgery, Ziekenhuisgroep Twente, Almelo, the Netherlands

S. M. Lagarde, MD PhD, Department of Surgery, Erasmus University Medical Center, Rotterdam, the Netherlands

G. A. P. Nieuwenhuijzen, MD PhD, Department of Surgery, Catharina Hospital, Eindhoven, the Netherlands

D. L. van der Peet, MD PhD, Department of Surgery, Amsterdam UMC, Vrije Universiteit, Amsterdam, the Netherlands

J. W. van Sandick, MD PhD, Department of Surgery, Antoni van Leeuwenhoek Hospital, Amsterdam, the Netherlands

A. K. Talsma, MD PhD, Department of Surgery, Deventer Ziekenhuis, Deventer, the Netherlands

G. W. M. Tetteroo, MD PhD, Department of Surgery, Ysselland Hospital, Rotterdam, the Netherlands

Author contributions - Substantial contributions to the conception or design of the work; or the acquisition, analysis, or interpretation of data for the work: LW, WE, WD, BE, SG, EH, ML, VL, BW, MB, MBH

- Drafting the work or revising it critically for important intellectual content; LW, WE, WD, BE, SG, EH, ML, VL, BW, MB, MBH.

- Final approval of the version to be published; LW, WE, WD, BE, SG, EH, ML, VL, BW, MB, MBH.

- Agreement to be accountable for all aspects of the work in ensuring that questions related to the accuracy or integrity of any part of the work are appropriately investigated and resolved. $\mathrm{LW}, \mathrm{WE}, \mathrm{WD}, \mathrm{BE}, \mathrm{SG}, \mathrm{EH}$, ML, VL, BW, MB, MBH

Open Access This article is distributed under the terms of the Creative Commons Attribution 4.0 International License (http:// creativecommons.org/licenses/by/4.0/), which permits unrestricted use, distribution, and reproduction in any medium, provided you give appropriate credit to the original author(s) and the source, provide a link to the Creative Commons license, and indicate if changes were made.

Publisher's Note Springer Nature remains neutral with regard to jurisdictional claims in published maps and institutional affiliations.

\section{References}

1. Oncoline. Guideline gastric cancer Version: 2.2. In. http://www. oncoline.n1/maagcarcinoom: Oncoline 2017-03-01.

2. Shchepotin IB, Chorny VA, Nauta RJ et al. Extended surgical resection in T4 gastric cancer. Am J Surg 1998; 175: 123-126.

3. Isozaki H, Tanaka N, Tanigawa N, Okajima K. Prognostic factors in patients with advanced gastric cancer with macroscopic invasion to adjacent organs treated with radical surgery. Gastric Cancer 2000; 3: 202-210.

4. Csendes A, Burdiles P, Rojas $\mathrm{J}$ et al. A prospective randomized study comparing D2 total gastrectomy versus D2 total gastrectomy plus splenectomy in 187 patients with gastric carcinoma. Surgery 2002; 131: 401-407.

5. Yu W, Choi GS, Chung HY. Randomized clinical trial of splenectomy versus splenic preservation in patients with proximal gastric cancer. Br J Surg 2006; 93: 559-563.

6. Sano T, Sasako M, Mizusawa J et al. Randomized Controlled Trial to Evaluate Splenectomy in Total Gastrectomy for Proximal Gastric Carcinoma. Ann Surg 2017; 265: 277-283.

7. Hartgrink HH, Velde CJHvd, Putter H et al. Extended Lymph Node Dissection for Gastric Cancer: Who May Benefit? Final Results of the Randomized Dutch Gastric Cancer Group Trial. Journal of Clinical Oncology 2004; 22: 2069-2077.

8. Cuschieri A, Fayers P, Fielding J et al. Postoperative morbidity and mortality after D1 and D2 resections for gastric cancer: preliminary results of the MRC randomised controlled surgical trial. The Surgical Cooperative Group. Lancet 1996; 347: 995-999.

9. Bonenkamp JJ, Songun I, Hermans J et al. Randomised comparison of morbidity after D1 and D2 dissection for gastric cancer in 996 Dutch patients. Lancet 1995; 345: 745-748.

10. Busweiler LA, Wijnhoven BP, van Berge Henegouwen MI et al. Early outcomes from the Dutch Upper Gastrointestinal Cancer Audit. Br J Surg 2016; 103: 1855-1863.

11. Charlson ME, Pompei P, Ales KL, MacKenzie CR. A new method of classifying prognostic comorbidity in longitudinal studies: Development and validation. Journal of Chronic Diseases 1987; 40: 373-383.

12. Bassi C, Dervenis C, Butturini G et al. Postoperative pancreatic fistula: an international study group (ISGPF) definition. Surgery 2005; 138: 8-13.

13. Carboni F, Lepiane P, Santoro R et al. Extended multiorgan resection for T4 gastric carcinoma: 25-year experience. J Surg Oncol 2005; 90: 95-100.

14. Jeong O, Choi WY, Park YK. Appropriate selection of patients for combined organ resection in cases of gastric carcinoma invading adjacent organs. J Surg Oncol 2009; 100: 115-120.

15. D'Amato A, Santella S, Cristaldi M et al. The role of extended total gastrectomy in advanced gastric cancer. Hepatogastroenterology 2004; 51: 609-612.

16. Saito H, Tsujitani S, Maeda Y et al. Combined resection of invaded organs in patients with T4 gastric carcinoma. Gastric Cancer 2001; 4: 206-211.

17. Brar SS, Seevaratnam R, Cardoso R et al. Multivisceral resection for gastric cancer: a systematic review. Gastric Cancer 2012; 15: 100-107.

18. Tran TB, Worhunsky DJ, Norton JA et al. Multivisceral Resection for Gastric Cancer: Results from the US Gastric Cancer Collaborative. Ann Surg Oncol 2015; 22 Suppl 3: S840-847.

19. Kwee RM, Kwee TC. Imaging in local staging of gastric cancer: a systematic review. J Clin Oncol 2007; 25: 2107-2116.

20. Beck N, Busweiler LAD, Schouwenburg MG et al. Factors contributing to variation in the use of multimodality treatment in patients with gastric cancer: A Dutch population based study. Eur J Surg Oncol 2018; 44: 260-267.

21. Cunningham D, Allum WH, Stenning SP et al. Perioperative chemotherapy versus surgery alone for resectable gastroesophageal cancer. N Engl J Med 2006; 355: 11-20.

22. Schouwenburg MG, Busweiler LAD, Beck $\mathrm{N}$ et al. Hospital variation and the impact of postoperative complications on the use of perioperative chemo(radio)therapy in resectable gastric cancer. Results from the Dutch Upper GI Cancer Audit. Eur J Surg Oncol 2018.

23. Slagter AE, Jansen EPM, van Laarhoven HWM et al. CRITICS-II: a multicentre randomised phase II trial of neo-adjuvant 
chemotherapy followed by surgery versus neo-adjuvant chemotherapy and subsequent chemoradiotherapy followed by surgery versus neo-adjuvant chemoradiotherapy followed by surgery in resectable gastric cancer. BMC Cancer 2018; 18: 877.

24. Martin RC, 2nd, Jaques DP, Brennan MF, Karpeh M. Extended local resection for advanced gastric cancer: increased survival versus increased morbidity. Ann Surg 2002; 236: 159-165.

25. van Rijssen LB, Koerkamp BG, Zwart MJ et al. Nationwide prospective audit of pancreatic surgery: design, accuracy, and outcomes of the Dutch Pancreatic Cancer Audit. HPB (Oxford) 2017; 19: 919-926.
26. Mita K, Ito H, Katsube $\mathrm{T}$ et al. Prognostic Factors Affecting Survival After Multivisceral Resection in Patients with Clinical T4b Gastric Cancer. J Gastrointest Surg 2017; 21: 1993-1999.

27. Cheng CT, Tsai CY, Hsu JT et al. Aggressive surgical approach for patients with T4 gastric carcinoma: promise or myth? Ann Surg Oncol 2011; 18: 1606-1614.

28. van Putten M, Verhoeven RH, van Sandick JW et al. Hospital of diagnosis and probability of having surgical treatment for resectable gastric cancer. Br J Surg 2016; 103: 233-241. 